\title{
Cardiothoracic surgery training grants provide protected research time vital to the development of academic surgeons
}

Adishesh K. Narahari, MS, ${ }^{a}$ Eric J. Charles, MD, PhD, ${ }^{a}$ J. Hunter Mehaffey, MD, MSc, ${ }^{a}$

Robert B. Hawkins, MD, MSc, ${ }^{a}$ Sarah A. Schubert, MD, ${ }^{a}$ Curtis G. Tribble, MD, ${ }^{a}$

Richard B. Schuessler, PhD, ${ }^{b}$ Ralph J. Damiano, Jr, MD, ${ }^{b}$ and Irving L. Kron, MD $^{\mathrm{a}}$

\section{ABSTRACT}

Background: The Ruth L. Kirschstein Institutional National Research Service Award (T32) provides institutions with financial support to prepare trainees for careers in academic medicine. In 1990, the Cardiac Surgery Branch of the National Heart, Lung and Blood Institute (NHLBI) was replaced by T32 training grants, which became crucial sources of funding for cardiothoracic (CT) surgical research. We hypothesized that T32 grants would be valuable for CT surgery training and yield significant publications and subsequent funding.

Methods: Data on all trainees (past and present) supported by CT T32 grants at two institutions were obtained (T32), along with information on trainees from two similarly sized programs without CT T32 funding (Non-T32). Data collected were publicly available and included publications, funding, degrees, fellowships, and academic rank. Non-surgery residents and residents who did not pursue CT surgery were excluded.

Results: Out of 76 T32 trainees and 294 Non-T32 trainees, data on 62 current trainees or current CT surgeons (T32: 42 vs Control: 20) were included. Trainees who were supported by a CT T32 grant were more likely to pursue CT surgery after residency (T32: 40\% [30/76] vs Non-T32: 7\% [20/294], $P<.0001$ ), publish manuscripts during residency years $(P<.0001)$, obtain subsequent $\mathrm{NIH}$ funding (T32: 33\% [7/21] vs Non-T32: $5 \%$ [1/20], $P=.02$ ), and pursue advanced fellowships (T32: $41 \%$ [9/22] vs Non-T32: 10\% [2/20], $P=.02$ ).

Conclusions: T32 training grants supporting CT surgery research are vital to develop academic surgeons. These results support continued funding by the NHLBI to effectively develop and train the next generation of academic CT surgeons. (J Thorac Cardiovasc Surg 2018;155:2050-6)

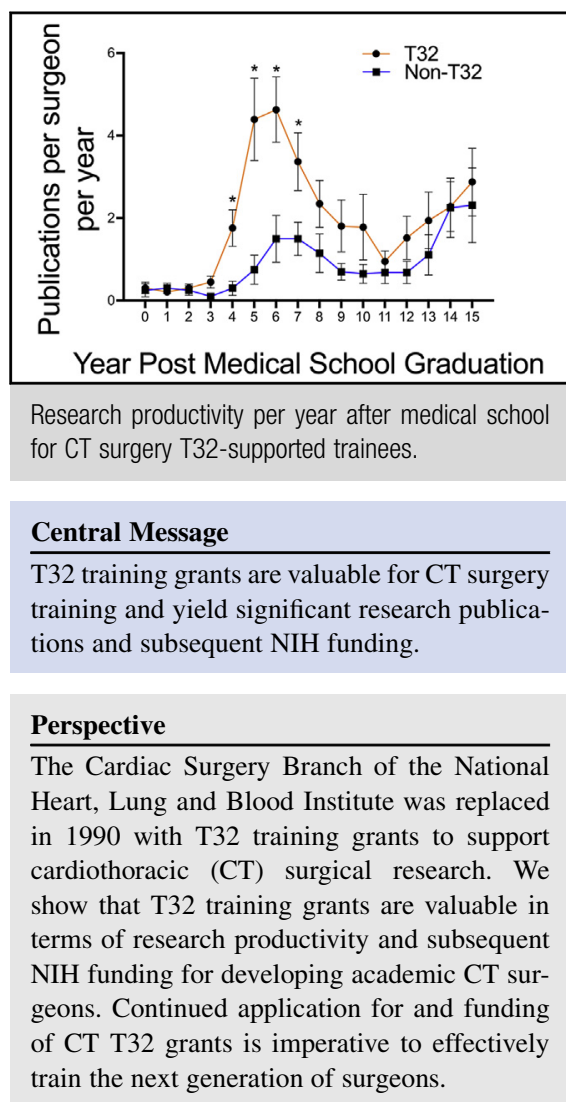

See Editorial Commentary page 2057.
From the a Division of Thoracic and Cardiovascular Surgery, Department of Surgery, University of Virginia, Charlottesville, Va; and ${ }^{\mathrm{b}}$ Division of Cardiothoracic Surgery, Department of Surgery, Washington University School of Medicine, St Louis, Mo.

Drs Narahari and Charles are co-first authors.

This work was supported by the National Institutes of Health (Grants T32 HL007849, UM1 HL088925, and T32 GM007267).

Read at the 97th Annual Meeting of The American Association for Thoracic Surgery, Boston, Massachusetts, April 29-May 3, 2017.

Received for publication April 30, 2017; revisions received Nov 21, 2017; accepted for publication Dec 7, 2017; available ahead of print Jan 17, 2018

Address for reprints: Irving L. Kron, MD, University of Virginia Health System, PO Box 800679, Charlottesville, VA 22908 (E-mail: ilk@ virginia.edu).

$0022-5223 / \$ 36.00$

Copyright (c) 2017 by The American Association for Thoracic Surgery

https://doi.org/10.1016/j.jtcvs.2017.12.041
The Cardiac Surgery Branch of the National Heart, Lung and Blood Institute (NHLBI) at the National Institutes of Health (NIH) was phased out in 1990 due to low clinical demand for the program. In a letter to the editor of the Annals of Thoracic Surgery, Dr Claude Lenfant stated that "Some have interpreted the phasing out of the intramural cardiac surgery program of the NHLBI as evidence of a declining

Scanning this QR code will take you to the article title page. 


\section{Abbreviations and Acronyms \\ $\mathrm{CT}=$ cardiothoracic \\ $\mathrm{NIH}=$ National Institutes of Health \\ NHLBI $=$ National Heart, Lung, and Blood Institute \\ T32 = Ruth L. Kirschstein Institutional National Research Service Award}

interest on the part of the NHLBI in supporting extramural research related to cardiothoracic surgery." "Following the closing of the NHLBI's Cardiac Surgery Branch in 1990, extramural sources of funding to support cardiothoracic (CT) surgery research training became crucial.

The NIH established the Ruth L. Kirschstein Institutional National Research Service Award (more commonly known as the T32 training grant) to "enable institutions to recruit individuals selected by them for predoctoral and postdoctoral research training in specified shortage areas."2 T32 awards were expected to provide extramural funding for cardiothoracic surgery programs to support necessary research training after the Cardiac Surgery Branch was phased out. Although the Cardiac Surgery Branch was actually reestablished in 2000 , it was integrated into the existing cardiology research program; thus, it was not meant to compete with extramural funding opportunities. Thus, T32 training grants remained the main source of extramural funding to support CT surgical research training. ${ }^{3}$ Currently, only 2 CT surgery $\mathrm{T} 32$ training grants are funded: Washington University School of Medicine in St Louis and the University of Virginia School of Medicine. ${ }^{4}$ Washington University School of Medicine's T32, titled "Basic Science Research Training-Cardiopulmonary Surgery," started in 1994, has received a total of \$4.3 million. University of Virginia's T32, "Cardiovascular Surgery Training Program," started in 1998 and has received a total of \$3.6 million. ${ }^{4}$

During its operation from 1953 to 1990, the Cardiac Surgery Branch trained 170 surgeons who went on to become academic leaders in CT surgery. LaPar and colleagues ${ }^{5}$ reported a decline in CT surgery research funding and called for more CT surgery research training programs. One of the major problems with the decline in NIH funding is the decrease in the number of applications from CT surgeons. CT surgeons are not currently applying for as much NIH funding, possibly due to their demanding schedules in the operating room. Decreased protected research time, high clinical demands, and ever- increasing competitiveness for NIH funding has led to CT surgeons being funded at lower rates than other clinicians. ${ }^{6}$ One report has advocated for separate criteria for the NIH to fund surgeon-scientists due to their very different work paradigm compared with other scientists or clinician-scientists. ${ }^{\text {? }}$
The objective of this study was to evaluate the research productivity and career trajectories of trainees (past and present) who were supported by the 2 active CT surgery T32 training grants. With potential NIH budget cuts looming, understanding the value of various funding mechanisms, such as T32 training grants, is paramount for ensuring continued medical advances. We hypothesized that T32 training grants support the development of academic CT surgeons, increase the yield of publications, and produce more $\mathrm{NIH}$-funded $\mathrm{CT}$ surgeon-scientists.

\section{METHODS \\ Selection of Trainees}

This study evaluated all trainees supported by The Ruth L. Kirschstein Institutional National Research Service Award (T32) at 2 institutions with CT surgery T32 grants: The University of Virginia School of Medicine (1998-present) and The Washington University School of Medicine in St Louis (1994-present) (PIs, Drs Irving L. Kron and Ralph J. Damiano Jr, respectively). Two similar-sized institutions with dedicated research time but no CT surgery T32 grants were selected as a control group (non-T32). The non-T32 group includes graduates going back to 1984. A diagram of the number of trainees evaluated is shown in Figure 1.

We used the following criteria for selecting our non-T32 group: (1) train between 5 and 8 categorical general surgery residents per year; (2) publish a publicly available graduate list dating back at least 10 years (2007); (3) have a strong history of residents who pursue CT surgery training (at least 5 CT surgery fellowship pursuits by general surgery residents in graduates list); (4) have a CT surgery fellowship program at the institution; (5) not have a Vascular Surgery T32 Training Grant, which may train residents who pursue CT surgery and have similarities to CT T32 grants; and (6) have a program in place for residents to perform research between postgraduate years 2 and 3 . Nonsurgical residents and residents who did not pursue CT surgery after residency were excluded from the analysis.

\section{Publication Data of Trainees}

Trainees' names were searched using the author filter on the National Center for Biotechnology Information's Website (https://www.ncbi.nlm. nih.gov/pubmed). ${ }^{8}$ All common combinations of each name were searched, including "last name, first and middle initials"; "last name, first name"; "last name, first name, and middle initial"; and "last name, first name initial." Names and institutions were cross-referenced with lists of T32 trainees and publicly available residency graduate lists. Each publication's author list with affiliations was reviewed by 1 of 2 reviewers to ensure that it should be attributed to the intended individual included in the study. Publications were binned by year for each trainee.

\section{Current Status of Trainees and Medical School Graduation Year}

The current position of trainees was obtained from the faculty pages of departments at academic institutions. Private practice surgeons were identified by publicly available practice or hospital websites. Medical school graduation year was established using available T32 grant information as well as publicly available individual residency/faculty/provider profiles. Integrated I-6 residents were included in all analyses with current fellows because they had already committed to a career in CT surgery.

\section{NIH Funding Information}

The NIH Research Portfolio Online Reporting Tools (NIH RePORTER) was used to obtain NIH funding information for all trainees. ${ }^{4} \mathrm{NIH}$ 


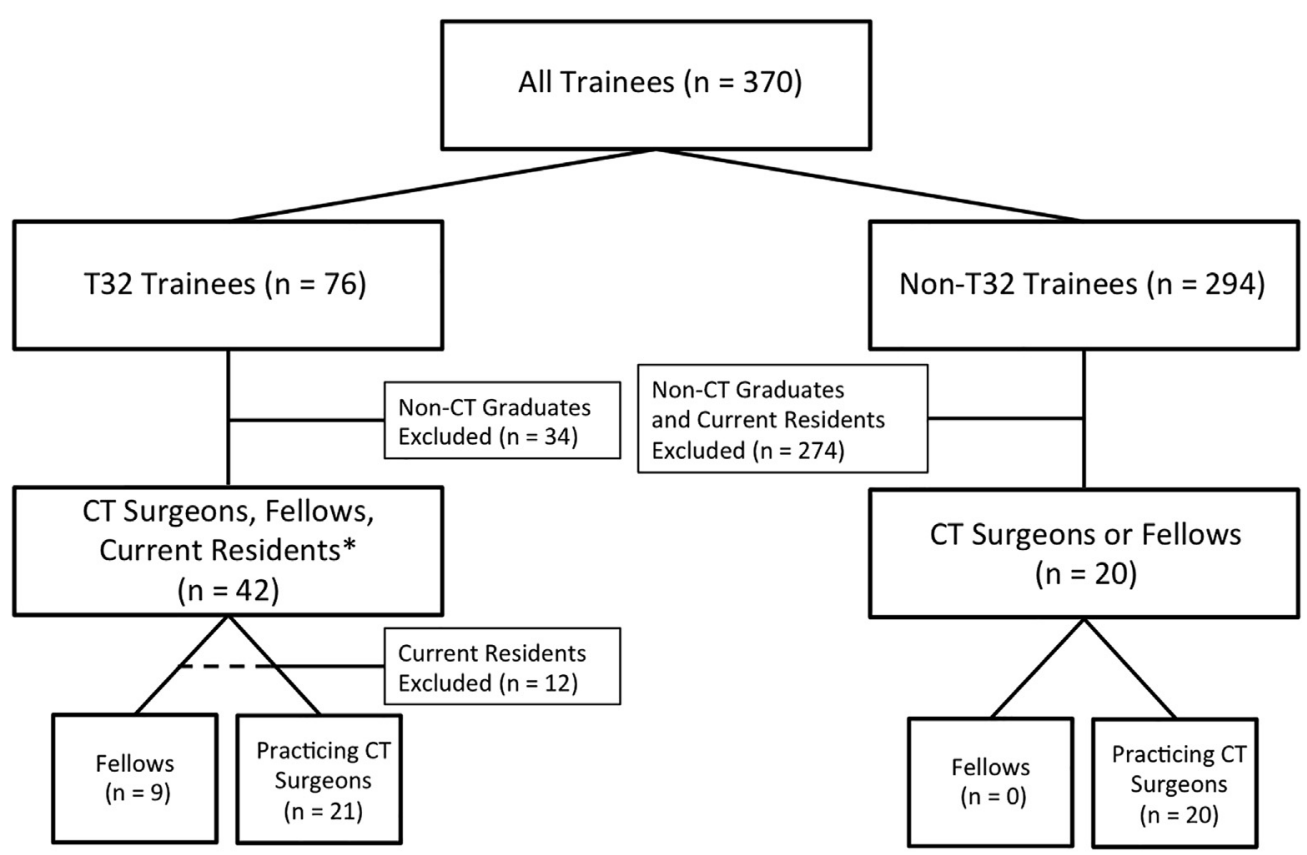

*T32 Current Residents Used For Publications Only

FIGURE 1. All trainees included in our study and the methodology for analysis is shown in a CONSORT flow diagram. *Current residents included on a T32 grant were used in the publications per surgeon per year analysis shown in Figure 2. T32, Ruth L. Kirschstein Institutional National Research Service Award; $C T$, cardiothoracic.

RePORTER contains NIH grant information dating back to 1993, including the following information for each NIH grant: principle investigator, investigator institution, investigator position, investigator department, publications, PMID for each publication, patents (from the US Patent and Trademark Office), years of funding, amount of funding, NIH administering institute, NIH study section, grant number, and grant title.

\section{Fellowship and Other Graduate Training Information}

Fellowship information and graduate degrees for all trainees were obtained from faculty pages, training grant information, or individual provider profiles. Advanced fellowships were considered to be any training beyond standard CT surgery training, such as congenital heart surgery, minimally invasive surgery, thoracic transplantation, adult cardiac surgery and transplantation, pediatric critical care, mechanical circulatory support, or aortic surgery. Additional graduate training included any additional degrees, such as master in public health, master in clinical science, and $\mathrm{PhD}$ degrees.

\section{Statistical Analysis}

The $\chi^{2}$ test was used to compare categorical data, 2-way analysis of variance was used to analyze the number of publications over time, and Student's $t$ test or the Mann-Whitney $U$ test was used for continuous variables. Continuous variables are presented as mean \pm standard error, and categorical data are presented as count and percentage. All analyses were performed using GraphPad Prism Version 7.00 (GraphPad Software La, Jolla, CA).

\section{RESULTS}

A total of 76 trainees (64 men and 12 women) who were supported by 1 of the $2 \mathrm{CT}$ surgery $\mathrm{T} 32$ training grants included in this study were identified. The non-T32 group comprised 294 residents, 20 (17 men and 3 women) of whom pursued careers in CT surgery and were included in our analyses.

\section{Publications}

T32 grant trainees (including current residents, current CT fellows, and practicing/attending CT surgeons;

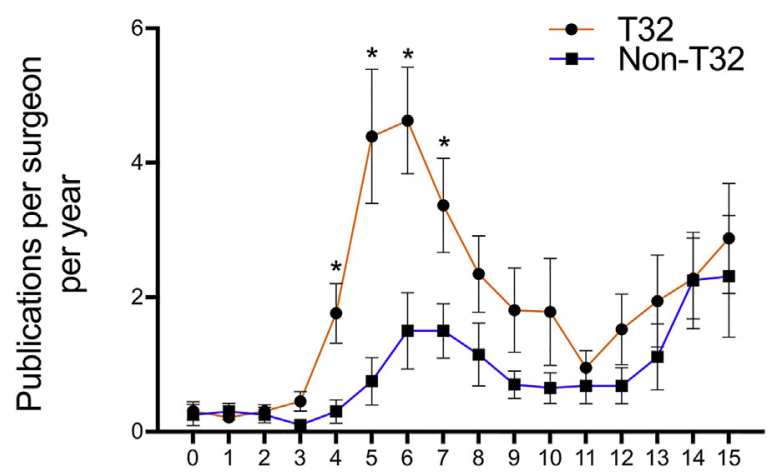

\section{Year Post Medical School Graduation}

FIGURE 2. Publications per surgeon per year for trainees supported by CT T32 funding (T32; $n=42$ ) and trainees who were not supported by CT T32 funding (non-T32; $\mathrm{n}=20$ ). Publications are reported for each year after graduation from medical school. ${ }^{*} P<.05$. T32, Ruth L. Kirschstein Institutional National Research Service Award. 
$\mathrm{n}=42)$ and non-T32 trainees who pursued careers in CT surgery $(n=20)$ were analyzed according to the number of manuscripts published per year per surgeon (Figure 2). Publications before residency matriculation are included in post-medical school year 0. T32 trainees published significantly more papers in post-medical school years 4 $(P=.04), 5(P<.0001), 6(P<.0001)$, and $7(P=.01)$. Post-medical school years 3 and 4 , or 4 and 5 are commonly the years devoted to dedicated basic science or clinical research. A bimodal distribution is seen for both T32 and non-T32 trainees, with peaks at 6 and 15 years following medical school graduation. There is no difference in the number of publications per year per surgeon after completion of residency.

\section{Pursuing CT Surgery and Academic Careers}

The distribution of trainees in residency, fellowship, and clinical practice is shown in Table 1. Excluding current general surgery residents (T32: $\mathrm{n}=12)$, there were 30 (28 men and 2 women) T32 CT surgeons (practicing/attending or current CT fellows). T32 trainees were more likely to pursue a career in CT surgery after their general surgery residency compared with non-T32 trainees (39.5\% [30 of 76] vs $6.8 \%$ [20 of 294]; $P<.0001$ ). There was no significant difference in the number of CT surgeons who completed fellowship training and elected to pursue a career in academic medicine (T32: $61.9 \%$ [13 of 21] vs non-T32: $45 \%$ [9 of 20]; $P=.28$ ).

\section{Publications and NIH Funding}

The number of publications and level of NIH funding for CT surgeons (practicing/attending or current CT fellow) are shown in Table 2. Total publications per CT surgeon were not statistically different between the 2 groups (T32: $36.6 \pm 6.1$ vs non-T32: $31.9 \pm 8.9 ; P=.21$ ); however,

TABLE 1. Distribution of trainees pursuing cardiothoracic surgery and academic careers

\begin{tabular}{lccc}
\hline \multicolumn{1}{c}{ Category } & T32, n (\%) & Non-T32, n (\%) & $\boldsymbol{P}$ value \\
\hline All trainees & 76 & 294 & - \\
CT surgeons* & $30(39.5)$ & $20(6.8)$ & $<.0001$ \\
Current fellow $\dagger$ & $9(30)$ & $0(0)$ & .01 \\
Assistant professor & $4(13.3)$ & $5(25)$ & .29 \\
Associate professor & $5(16.7)$ & $3(15)$ & .87 \\
Professor & $3(10)$ & $1(5)$ & .52 \\
Private practice & $8(26.7)$ & $11(55)$ & .04 \\
Researcher & $1(3.3)$ & $0(0)$ & .41 \\
Current residents & $12(15.8)$ & $88(29.9)$ & .01 \\
Other surgeons $\ddagger$ & $34(44.7)$ & $186(63.3)$ & $<.0001$ \\
\hline
\end{tabular}

T32, Ruth L. Kirschstein Institutional National Research Service Award; CT, cardiothoracic. $* \mathrm{CT}$ surgeons includes practicing/attending cardiothoracic surgeons and current cardiothoracic fellows. $\dagger$ Current fellows include integrated I- 6 cardiothoracic surgery residents. $\ddagger$ Other surgeons include all surgeons other than cardiothoracic surgeons. the T32 CT surgeons obtained more NIH grants (15 vs 2$)$ and were more likely to have current NIH funding (33.3\% [7 of 21$]$ vs $5 \%$ [ 1 of 20$] ; P=.02$ ). The T32 CT surgeons received more than $\$ 9$ million in funding, compared with $\$ 600,000$ for non-T32 CT surgeons (mean funding per surgeon: T32, $\$ 429,805 \pm \$ 256,884$ vs nonT32, $\$ 33,258 \pm \$ 33,258 ; P=.04)$. The majority of grant funding was in thoracic surgery, but 1 trainee received grants related to cardiac surgery. Five T32 CT surgeons and 1 non-T32 CT surgeon received additional funding in the form of a F32 grant (Ruth L. Kirschstein National Research Service Award Individual Postdoctoral Fellowship).

\section{Fellowship Training}

Twenty-two of the 30 trainees in the T32 group completed a 2-year or 3-year CT surgery fellowship (Table 3). The T32 trainees were more likely than nonT32 trainees to pursue advanced fellowships after completion of standard CT fellowship (40.9\% [9 of 22] vs $10 \%$ [2 of 20]; $P=.02$ ). In terms of advanced degrees, 2 of the $30 \mathrm{~T} 32$ trainees and 1 of the 20 non-T32 trainees obtained $\mathrm{PhDs}(P=.78)$, and $4 \mathrm{~T} 32$ trainees and 2 non-T32 trainees have masters degrees $(P=.78)$.

\section{DISCUSSION}

At a time when obtaining NIH funding is becoming more difficult, the academic CT surgeon-scientist's role in the advancement of scientific research is more important than ever. This study analyzed the effectiveness of all current T32 training grants to determine whether they provide any additional benefit compared with traditional training programs without CT T32 grants. Our data demonstrate that T32 grants are valuable for CT surgery training and lead to significant publications and subsequent funding. Trainees who were supported by CT T32 training grants were more likely to pursue CT surgery after residency, to publish more prolifically during residency years, to obtain subsequent NIH funding, and to pursue advanced fellowships. T32 training grants supporting CT surgery research appear to be vital to the development of academic surgeons.

In a recent study, Keswani and colleagues ${ }^{9}$ surveyed 1033 academic surgeons and their views on research. Unsurprisingly, academic surgeons stated that pressure to be productive in the operating room, administrative responsibilities, difficulty in obtaining funding, and wanting a good work-life balance as reasons for not pursuing basic science research. Surprisingly, however, $68 \%$ of respondents to the survey stated that they "did not believe surgeons can be successful basic scientists in today's environment." 9 These respondents also included department leaders. We believe that encouraging and training young surgeons to become proficient with basic science 
TABLE 2. Publications and National Institutes of Health funding

\begin{tabular}{lccc}
\hline \multicolumn{1}{c}{ Category } & T32 & Non-T32 & P value \\
\hline CT surgeons, $\mathrm{n} *$ & 30 & 20 & - \\
Total publications, $\mathrm{n}$ & 1099 & 639 & - \\
\hline Publications per surgeon, mean \pm SE & $36.6 \pm 6.1$ & $31.9 \pm 8.9$ & .21 \\
\hline Attending CT surgeons, $\mathrm{n} \dagger$ & 21 & 20 & - \\
Surgeons with NIH funding, $\mathrm{n}(\%)$ & $7(33.3)$ & $1(5 \%)$ & .02 \\
Total NIH grants, $\mathrm{n}(\%)$ & 15 & $1(50)$ & - \\
R01 awards & $1(6.7)$ & $1(50)$ & .08 \\
F32 awards & $5(33.3)$ & $0(0)$ & .64 \\
Other awards & $9(60)$ & 665,150 & .28 \\
Total NIH funding, $\$$ & $9,025,906$ & $33,258 \pm 33,258$
\end{tabular}

T32, Ruth L. Kirschstein Institutional National Research Service Award; $C T$, cardiothoracic; $S E$, standard error; $N I H$, National Institutes of Health. *CT surgeons include practicing/attending cardiothoracic surgeons and current cardiothoracic fellows. † $\dagger$ Attending $\mathrm{CT}$ surgeons include only practicing/attending cardiothoracic surgeons. Current fellows are excluded.

research is critical to mitigate current barriers to basic science research for surgeons.

The ability to master both the technical skills necessary to perform as a high-quality surgeon in the operating room and the research skills necessary to be a productive academician is challenging. Providing high-quality clinical care in the operating room has become increasingly demanding for surgeons, with no room for mediocre performance. ${ }^{10}$ In addition, the proportion of trainees pursuing basic science research in surgeon-scientist and clinician-investigator programs has decreased significantly over the past 30 years. ${ }^{11}$ An important factor in maintaining resident research training programs and continuing to encourage young surgeons to pursue productive academic careers is providing financial support for residents so they can learn the necessary research skills. The Ruth L. Kirschstein Institutional National Research Service Awards (T32) provide that support. Not only are research and academic interest down, CT surgery has lost some popularity among young trainees over the past 15 years as well. ${ }^{12}$ Therefore, to train the next generation of CT surgeon-scientists with a strong research background, extramural funding to provide these critical skills during residency is crucial.

In the present study, we found that trainees supported by CT T32 training grants publish prolifically, especially during the second half of residency. Compared with residents who pursued a career in CT surgery but were not supported by a T32 training grant, T32 trainees published a significantly greater number of manuscripts per year during residency (Figure 2). It appears as though the benefits of structured research training during residency, which a T32 training grant provides, yields immediate results. A structured training program will drive residents to set research goals and attain them. Likewise, the requirements of a
T32 training grant encourage mentors to establish an environment that promotes resident-driven research projects to achieve a level of productivity necessary to maintain a T32 grant. Furthermore, the grants support residents to purse advanced degrees and cover the expense of course work to teach these skills.

Interestingly, there is a bimodal distribution in publications for both the T32 group and the non-T32 group. The first peak in publications is during research years, and the second occurs after establishment in a faculty position. We found that faculty-level CT surgeons from both groups publish equally as they begin their professional careers. This research productivity during the early stages of an academic career is known to be quite important for the development of career surgeon-scientists. ${ }^{13}$ Over the course of their careers, T32 CT surgeons published more papers per surgeon compared with non-T32 trainees, but the difference was not statistically significant.

Moreover, the present study identified a relationship between trainees who are supported by a CT T32 training grant during residency and the likelihood that they will pursue a career in CT surgery. Compared with a cohort of general residents who did not have the opportunity to train in a CT T32 training grant, CT T32 trainees are significantly more likely to pursue CT surgery after completion of residency (Table 1). The percentage of CT surgeons who chose an academic career was similar regardless of $\mathrm{T} 32$ training grant status $(61.9 \%$ vs $45 \% ; P=.28)$, indicating that a large percentage of trainees who choose CT surgery as a career also choose an academic career regardless of $\mathrm{T} 32$ status.

However, NIH funding was significantly different between attending/practicing CT surgeons who were supported by a T32 during training and those who were not. 
TABLE 3. Advanced fellowship training and graduate degrees

\begin{tabular}{lccc}
\hline \multicolumn{1}{c}{ Category } & $\begin{array}{c}\text { T32, } \\
\mathbf{n}(\%)\end{array}$ & $\begin{array}{c}\text { Non-T32, } \\
\mathbf{n}(\%)\end{array}$ & $\boldsymbol{P}$ value \\
\hline Post-fellowship CT surgeons* & 22 & 20 & - \\
Advanced fellowships & $9(40.9)$ & $2(10)$ & .02 \\
Congenital & $5(55.5)$ & $0(0)$ & .15 \\
Other $\dagger$ & $4(44.4)$ & $2(100)$ & .15 \\
Graduate degrees & $6(27.2)$ & $4(20)$ & .58 \\
Masters & $4(66.6)$ & $3(75)$ & .78 \\
PhD & $2(33.3)$ & $1(25)$ & .78 \\
\hline
\end{tabular}

T32, Ruth L. Kirschstein Institutional National Research Service Award; $C T$, cardiothoracic. *Post-fellowship CT surgeons include practicing/attending cardiothoracic surgeons and 1 trainee currently enrolled in an advanced fellowship. †Other advanced fellowships include minimally invasive thoracic surgery, thoracic transplantation, and pediatric critical care.

CT T32 trainees obtained more NIH grants, and higher levels of funding, compared with non-T32 trainees. These findings suggest that research training from regimented T32 research programs likely contributes to future success in applying for and receiving NIH funding. T32 training programs are held accountable for ensuring adequate progress and execution of projects, teaching analysis skills, and generating well-rounded scientists with strong research foundations. These requirements train residents to be rigorous scientists with the skills necessary to compete successfully for NIH funding.

Finally, the present study evaluated any additional training surgeons have received above the standard MD degree with residency and a CT surgery residency (Table 3). CT T32 trainees received more advanced fellowship and other graduate training compared with non-T32 trainees. Academically inclined surgeons are more likely to pursue further graduate training and to choose to train in institutions with strong research training, such as institutions with a CT T32 grant.

This study has several limitations, including potential selection bias due to its retrospective nature. Trainees may specifically select a residency that has a CT T32 training grant because they are interested in CT surgery and obtaining a strong research foundation. Although this may constitute selection bias, it is an important factor when residents are selecting a residency. If a school aims to graduate general surgery residents who decide to pursue CT surgery fellowships, the presence of a CT surgery T32 will allow them to attract residents interested in CT surgery and give them the tools to train residents in CT surgery research. To provide a comparison group of residents not supported by a CT T32, we made an effort to use strict criteria to select similar-sized training programs that support dedicated research time but do not offer CT T32 support, although these may not be representative of all programs. Unfortunately, only 2 programs met our criteria for a control group. Additional schools meeting our criteria would be desirable for our study. Nonetheless, the present study identifies T32 training grants as a valuable asset for attending CT surgeons and institutions dedicated to training the next generation of academic CT surgeons.

A desire to enter academia and perform research is a key reason why residents decide to take 2 years during residency to perform research. ${ }^{14}$ Dedicated research years during training prepares residents for a career in academic medicine. Residents who participate in formal research training programs are more likely to have academic success compared with those who do not participate in formal research training. ${ }^{15}$ Studies have shown that participation by trainees in research during specialty training is a promising approach to academic careers. ${ }^{16}$ Mentorship is a critical requirement for basic science and clinical research success. Mentorship and institutional support are especially critical during the early stages of a practicing surgeon. Kodadek and colleagues ${ }^{17}$ found that mentorship is especially important for obtaining K-awards. A structured mentorship program ensures that trainees who want a mentor are paired with a mentor and protected time to dedicate to research is ensured. ${ }^{18}$ Finally, mentorship is critical in the training of operating skills for residents. ${ }^{19}$ A research environment with dedicated mentorship, protected time, and a structured plan are vital for training surgeon-scientists.

We have demonstrated that CT T32 training grants produce academically prolific CT surgeons. With an anticipated shortage of CT surgeons, we recommend that more schools be awarded CT T32 training grants to train cardiothoracic surgeons for the future. ${ }^{20}$ The trainees from CT T32 training grants publish more papers than their counterparts during residency training, and pursue CT surgery more frequently than their peers after residency. CT T32 trainees also obtain significantly more NIH funding and are more likely to obtain advanced fellowship training. Finally, T32 trainees are more likely to pursue additional graduate degrees. T32 training grants provide institutions with the financial means to support trainees interested in pursuing CT surgery research. These training grants demand that programs maintain a high level of rigor and infrastructure to ensure continuous funding, which appears to translate into CT surgeons with strong research foundations. It is important that institutions and attending CT surgeons apply for T32 support to develop successful CT surgeonscientists, and to encourage the NIH to continue funding these important training mechanisms.

\section{Conflict of Interest Statement}

Authors have nothing to disclose with regard to commercial support.

\footnotetext{
References

1. Lenfant C. The cardiac surgery program of the National Heart, Lung, and Blood Institute. Ann Thorac Surg. 1990;49:1023-4.
} 
2. Ruth L. Kirschstein Institutional National Research Service Award. Available at: https://researchtraining.nih.gov/programs/training-grants/T32. Accessed April 17, 2017.

3. Lenfant C. National Heart, Lung, and Blood Institute cardiothoracic surgery program: drawing from our past, building for our future. Circulation. 2000;102:1212-3.

4. National Institutes of Health. Research Portfolio Online Reporting Tools (RePORT). Available at: https://projectreporter.nih.gov/reporter.cfm. Accessed February 5, 2017.

5. LaPar DJ, Kron IL. Cardiothoracic surgery and the National Institutes of Health and National Heart, Lung, and Blood Institute. J Thorac Cardiovasc Surg. 2011;142:20-3.

6. Ratcliffe MB, Howard C, Mann M, del Nido P. National Institutes of Health funding for cardiothoracic surgical research. J Thorac Cardiovasc Surg. 2008;136: 392-7; discussion 398-9.

7. Niederhuber JE. An old problem that may be getting worse. Ann Surg. 2008;247: 222-3.

8. National Center for Biotechnology Information, U.S. National Library of Medicine Available at: https://www.ncbi.nlm.nih.gov/pubmed/. Accessed April 21, 2017.

9. Keswani SG, Moles CM, Morowitz M, Zeh H, Kuo JS, Levine MH, et al. The future of basic science in academic surgery: identifying barriers to success for surgeon-scientists. Ann Surg. 2017;265:1053-9.

10. Gittes GK. The surgeon-scientist in a new biomedical research era. Surgery. 2006;140:123-31.

11. Goldenberg NM, Steinberg BE, Rutka JT, Chen R, Cabral V, Rosenblum ND, et al. Research projects in the Surgeon-Scientist and Clinician-Investigator programs at the University of Toronto (1987-2016): a cohort study. CMAJ Open. 2016:4:E444-7.
12. Parissis H. Cardiac surgery: what the future holds? J Cardiothorac Surg. 2011;6: 93.

13. Kron IL. Getting promoted. J Thorac Cardiovasc Surg. 2001;121(4 Suppl): S17-8.

14. Stewart RD, Doyle J, Lollis SS, Stone MD. Surgical resident research in New England. Arch Surg. 2000;135:439-44.

15. Hsieh H, Paquette F, Fraser SA, Feldman LS, Meterissian S, Fried GM, et al. Formal research training during surgical residency: scaffolding for academic success. Am J Surg. 2014;207:141-5.

16. Wong MD, Guerrero L, Sallam T, Frank JS, Fogelman AM, Demer LL. Out comes of a novel training program for physician-scientists: integrating grad uate degree training with specialty fellowship. J Grad Med Educ. 2016;8: 85-90.

17. Kodadek LM, Kapadia MR, Changoor NR, Dunn KB, Are C, Greenberg JA, et al Educating the surgeon-scientist: a qualitative study evaluating challenges and barriers toward becoming an academically successful surgeon. Surgery. 2016; 160:1456-65.

18. Entezami P, Franzblau LE, Chung KC. Mentorship in surgical training: a systematic review. Hand (NY). 2012:7:30-6.

19. Kron IL. Surgical mentorship. J Thorac Cardiovasc Surg. 2011;142:489-92.

20. Grover A, Gorman K, Dall TM, Jonas R, Lytle B, Shemin R, et al. Shortage of cardiothoracic surgeons is likely by 2020. Circulation. 2009;120:488-94.

Key Words: T32, resident research, NIH funding, grants, cardiothoracic surgery training 